\title{
A metal-free approach for the hydrogenolysis of unactivated $\mathrm{C}$ (aryl) $-\mathrm{C}$ (alkyl) bonds
}

Huadong Wang ( $\nabla$ huadongwang@fudan.edu.cn )

Fudan University https://orcid.org/0000-0001-9129-0004

\section{Yuliang Xu}

Fudan University

\section{Yizhou Yang}

Fudan University

\section{Yizhen Liu}

Fudan University

\section{Zhen Li}

Fudan University

\section{Article}

Keywords: $\mathrm{C}-\mathrm{C}$ bonds, borenium complex, alkylarenes

Posted Date: November 5th, 2021

DOI: https://doi.org/10.21203/rs.3.rs-960416/v1

License: (c) (i) This work is licensed under a Creative Commons Attribution 4.0 International License. Read Full License

Version of Record: A version of this preprint was published at Nature Catalysis on December 23rd, 2022. See the published version at https://doi.org/10.1038/s41929-022-00888-y. 


\section{Abstract}

The hydrogenolysis of $\mathrm{C}-\mathrm{C}$ bonds is among one of the most important processes in the petroleum industry which has been considered as a viable way to recycle waste polyolefins. These transformations typically rely on heterogeneous catalysts and take place at high temperature and high pressure with limited selectivity. Employing homogenous transition metal catalysts, while allowing the hydrogenolysis of $\mathrm{C}-\mathrm{C}$ bonds to proceed under much milder conditions, is only suitable for substrates containing strained $\mathrm{C}-\mathrm{C}$ bonds or directing groups. Here we report that a borenium complex can catalyze the selective hydrogenolysis of unstrained $\mathrm{C}($ aryl) $-\mathrm{C}(\mathrm{alkyl})$ bonds of alkylarenes at ambient temperature, affording the corresponding alkanes and arenes. This method does not require the assistance of directing groups, and tolerates a range of functional groups. Mechanistic studies suggest a reaction pathway that involves a synergistic activation of dihydrogen by the borenium complex and alkylarenes, followed by retro-Friedel-Crafts reaction to cleave the $\mathrm{C}(\mathrm{aryl})-\mathrm{C}(\mathrm{alkyl})$ bonds. The synthetic utility of this protocol was demonstrated by the conversion of post-consumer polystyrene into valuable benzene and phenylalkanes with mass recovery above $90 \%$, thus opening up new avenues for the recycling of aromatic chemicals from waste plastics.

\section{Main Text}

The catalytic hydrogenolysis of $\mathrm{C}-\mathrm{C}$ bonds, a process involving rupture of $\mathrm{C}-\mathrm{C}$ bonds via reaction with dihydrogen, plays a central role in the petroleum industry, upgrading low-value feedstocks to high-value fuels or commodity chemicals. ${ }^{1-3}$ Recently, the hydrogenolysis of $\mathrm{C}-\mathrm{C}$ bonds also attracted attention as a viable way for the chemical recycling of polyolefin plastic waste. ${ }^{4,5}$ Due to the large bond dissociation energy and non-polar nature of $\mathrm{C}-\mathrm{C}$ bonds, industrial hydrogenolysis of $\mathrm{C}-\mathrm{C}$ bonds typically takes place at temperatures above $300^{\circ} \mathrm{C}$ with high-pressure hydrogen (40 to $200 \mathrm{bar}$ ). The substantial energy requirements of this process provide a strong incentive to develop catalytic systems which can operate at ambient conditions. A number of homogenous hydrogenolysis of $\mathrm{C}-\mathrm{C}$ bonds have been reported using transition metal catalysts. ${ }^{6}$ The key step in these transformations is the cleavage of $\mathrm{C}-\mathrm{C}$ bonds via oxidative addition, which takes place prior to the activation of $\mathrm{H}_{2}$. However, to ensure that the oxidative addition of steric shielded $\mathrm{C}-\mathrm{C}$ bonds can outcompete more accessible $\mathrm{C}-\mathrm{H}$ bonds, specifically designed substrates, such as those incorporated with strained $C-C$ bonds ${ }^{7-9}$ or pre-installed directing groups, ${ }^{10-13}$ are required, thereby limiting the scope of this approach.

In recent decades, main-group-element-based systems have drawn a surging interest as a result of their potential to mimic or even transcend the reactivities of their transition metal counterparts in catalysis. ${ }^{14-}$ ${ }^{16}$ Aiming to circumvent the inherent limitation associated with transition metal catalysts in $\mathrm{C}-\mathrm{C}$ bond hydrogenolysis, we set out to explore the possibility of main-group-element based catalysts for the hydrogenolysis of unstrained $\mathrm{C}-\mathrm{C}$ bonds in the absence of directing groups. We chose the hydrogenolysis of the $\mathrm{C}(\mathrm{aryl})-\mathrm{C}(\mathrm{alkyl})$ bonds of alkylarenes as our target. This transformation, known as hydrodealkylation, plays an important role in the production of arenes in the petroleum 
industry (Figure 1A). 2,3,17 The presence of unsaturated arene moieties in this transformation, however, represents an extra challenge because of competing arene hydrogenation reactions. ${ }^{18}$ The sole example of homogenous hydrogenolysis of unactivated $C($ aryl $)-C\left(\right.$ alkyl) bonds was reported by Milstein et al., ${ }^{10}$ in which methylarenes with two pendant phosphine arms can be converted to the corresponding arenes and methane in the presence of Rh catalysts under $\mathrm{H}_{2}$ at $150^{\circ} \mathrm{C}$ (Figure 1B). The two phosphine moieties, which cannot be readily removed, are indispensable for the observed reactivity, as the formation of stable metallacycle intermediates provides the driving force for the oxidative addition of the $\mathrm{C}($ aryl $)-\mathrm{C}($ alkyl) bond. ${ }^{19}$ Our hydrodealkylation approach was inspired by frustrated Lewis pair chemistry pioneered by Stephan and Erker. ${ }^{20-22}$ One of the most important discoveries in this field is that $\mathrm{H}_{2}$ can be heterolytically cleaved when simultaneously interacting with an electron donor and an electron acceptor. ${ }^{23,24}$ We questioned if an alkylarene, as a $\pi$-electron donor, is capable of activating $\mathrm{H}_{2}$ in the presence of a Lewis acid, which would lead to the formation of a hydride species and a Wheland complex (Figure 1C). A retro-Friedel-Crafts reaction of the Wheland complex would yield the arene and a carbenium intermediate. ${ }^{25,26}$ Subsequent hydride abstraction from the generated hydride species by the carbenium intermediate would afford the alkane and the Lewis acid catalyst, thus completing the catalytic cycle. Given that alkylarenes are much weaker electron-donors than Lewis bases typically applied in frustrated Lewis pair chemistry (such as amines and phosphines), we reasoned that an exceptionally strong Lewis acid with high hydride affinity would be needed for smooth $\mathrm{H}_{2}$ activation under mild conditions. ${ }^{23,24}$ Furthermore, steric protection around the Lewis acid center will be necessary to hinder the hydride transfer from the Lewis acid center to the Wheland complex, a side reaction which would lead to the hydrogenation of aromatic rings. ${ }^{27}$ Recently, we reported the synthesis of an $\mathrm{N}$ heterocyclic carbene (1,3-bis(2,3,4,5,6-pentafluorobenzyl)imidazol-2-ylidene, IBn ${ }^{\mathrm{F}}$ ) stabilized o-carboranylsubstituted borenium complex $1 \mathrm{a}$, which is Lewis acidic enough to activate methane under relatively mild conditions. ${ }^{28}$ This prompted us to explore the catalytic activity of $1 \mathbf{a}$ in the hydrodealkylation of unfunctionalized alkylarenes.

We began our study by choosing (1,1-dimethylpropyl)benzene (2) as the model substrate. Combining 2 with 10 mole percent (mol\%) of $1 \mathrm{a}$ under 1 bar of $\mathrm{H}_{2}$ in bromobenzene resulted in the formation of benzene and isopentane with $97 \%$ and $91 \%$ yields respectively as determined by gas-chromatographymass spectrometry (GC-MS) after 24 hours at $25^{\circ} \mathrm{C}$ (Table S1). Increasing the pressure of $\mathrm{H}_{2}$ to 20 bar allows the reaction to reach full conversion with a much lower catalyst loading ( $1 \mathrm{~mol} \%)$. No arene hydrogenation products were formed under this reaction condition as indicated by the ${ }^{13} \mathrm{C}\left\{{ }^{1} \mathrm{H}\right\} \mathrm{NMR}$ spectrum of the crude reaction mixture (Figure S2). Other haloarenes, such as $\mathrm{C}_{6} \mathrm{H}_{5} \mathrm{Cl}_{1} \mathrm{C}_{6} \mathrm{H}_{5} \mathrm{~F}$ or $0-\mathrm{C}_{6} \mathrm{H}_{4} \mathrm{~F}_{2}$, are also suitable solvents for the hydrodealkylation reaction. In the absence of $\mathrm{H}_{2}$, both $\mathbf{2}$ and $\mathbf{1 a}$ remained unchanged in $\mathrm{C}_{6} \mathrm{D}_{5} \mathrm{Br}$ after 24 hours at $25^{\circ} \mathrm{C}$. Replacing $1 \mathrm{a}$ with less electrophilic $\left[\mathrm{IMe}_{4} \mathrm{~B}(\mathrm{H}) \mathrm{Cb}\right]$ $\left[\mathrm{B}\left(\mathrm{C}_{6} \mathrm{~F}_{5}\right)_{4}\right]\left(\mathrm{IMe}_{4}=1,3,4,5\right.$-tetramethylimidazol-2-ylidene, $\mathrm{Cb}=$ o-carboran-1-yl, 1b) ${ }^{29}$ resulted in lower yields ( $23 \%$ and $5 \%$ for benzene and isopentane respectively) even at $50^{\circ} \mathrm{C}$ (Table S1). Neutral organoborane $\mathrm{B}\left(\mathrm{C}_{6} \mathrm{~F}_{5}\right)_{3}$ and strong $\mathrm{Brønsted}$ acid $\mathrm{CF}_{3} \mathrm{SO}_{3} \mathrm{H}$ are completely ineffective as catalysts. 
With our optimized conditions in hand, we explored the scope of this transformation, starting with the alkyl moieties of the alkylarenes (Figure 2). Tertiary-alkyl substituted benzenes, such as $t$ butylbenzene (3) and 1-phenyl-adamantane (4), were efficiently converted to benzene and the corresponding alkanes. Secondary-alkyl substituted benzenes (5-10) are also suitable substrates. Interestingly, for 1-(4-chlorophenyl)-1-phenylethane (8), the formation of benzene is favored over electronpoor chlorobenzene, in agreement with the proposed role of arenes as $\pi$-bases in the $\mathrm{H}_{2}$ activation process. For 1-phenyltetralin (9), selective hydrogenolysis of the exo-ring $\mathrm{C}($ aryl) $-\mathrm{C}($ alkyl) bond was observed. Cumene (11) suffers competing transalkylation, which affords alkylated bromobenzene as a byproduct due to the reaction between 2-propyl cation intermediate and solvent bromobenzene. Similarly, diphenylmethane (12) also undergoes transalkylation to yield benzene and alkylated bromobenzene. When the phenyl groups of diphenylmethane were replaced with bulkier mesityl groups, the reaction proceeded smoothly to yield mesitylene and 1,2,3,5-tetramethylbenzene in $0-\mathrm{C}_{6} \mathrm{H}_{4} \mathrm{~F}_{2}$. Toluene and ethylbenzene failed to undergo hydrogenolysis even with $20 \mathrm{~mol} \%$ of $1 \mathrm{a}$ at $50^{\circ} \mathrm{C}$ under 20 bar of $\mathrm{H}_{2}$ (Figure S32).

Subsequently, the scope of the arene moiety was investigated (Figure 2). Functional groups, such as primary alkyl (14-18), fluoro, chloro and bromo groups (20-22) are tolerated, although the substrates with electron-withdrawing groups require higher catalyst loading. While weakly coordinating methoxy group (19) is tolerated, albeit at slightly elevated temperatures and increased catalyst loading, the presence of stronger coordinating functional groups, such as amino and ester, however, completely inhibited the hydrogenolysis reaction (Figure S32). For the substrates containing $C($ aryl) $-C$ (aryl) bonds (23, 24 and 28), only the $C($ aryl $)-C(a l k y l)$ bonds were selectively cleaved. Hydrogenolysis of 1-(4chlorophenyl)-1-(2-naphthyl)ethane (25) led to partial reduction of naphthalene to give tetralin. Dialkylsubstituted arenes (26-29) undergo double $\mathrm{C}-\mathrm{C}$ bond hydrogenolysis, affording the corresponding arenes and alkanes. Heteroarenes, such as alkyl-substituted dibenzofuran (30) and xanthene (31), are compatible with the reaction conditions. This catalytic system can also be applied to a gram scale reaction, where $1.33 \mathrm{~g}$ of $\mathbf{2 8}$ undergoes hydrogenolysis to yield biphenyl in $93 \%$ isolation yield.

To understand the mechanism of this hydrodealkylation reaction, we conducted kinetic experiments to determine the order of the reaction in each reactant by monitoring the hydrogenolysis of 6 in $\mathrm{C}_{6} \mathrm{D}_{5} \mathrm{Br}$ by ${ }^{1} \mathrm{H}$ NMR analysis. Throughout the reaction, 1 a remained the only observable $\mathrm{IBn}^{\mathrm{F}}$-coordinated complex as indicated by ${ }^{1} \mathrm{H}$ and ${ }^{19} \mathrm{~F}$ NMR spectra, revealing $1 \mathrm{a}$ as the resting state with respect to the catalytic boron component. The reaction displayed first-order dependence on catalyst $1 \mathrm{a}, 6$ and the pressure of $\mathrm{H}_{2}$ (Figure S33, S36, S41). This is consistent with our proposed reaction pathway entailing synergistic activation of $\mathrm{H}_{2}$ with $\mathbf{1 a}$ and $\mathbf{6}$. The involvement of $\mathrm{H}_{2}$ in the rate law also indicates that the activation of $\mathrm{H}_{2}$ takes place either prior to or during the turnover-determining step. Replacing $\mathrm{H}_{2}$ with $\mathrm{D}_{2}$ resulted in the formation of $\mathrm{C}_{6} \mathrm{H}_{5} \mathrm{D}$ and $\left(\mathrm{CH}_{3}\right) \mathrm{C}(\mathrm{D})(\mathrm{H})\left(\mathrm{C}_{6} \mathrm{H}_{5}\right)$, as determined by the ${ }^{2} \mathrm{H}$ NMR spectrum (Figure S48). 11111111sssMeasuring the rate constants in the presence of $\mathrm{H}_{2}$ or $\mathrm{D}_{2}$ led to the determination of a kinetic isotope effect (KIE) of 1.17 (Figure $3 \mathrm{~A}$ ). Furthermore, Eyring analysis over a $40^{\circ} \mathrm{C}$ range (50 to 
$90^{\circ} \mathrm{C}$, Figure S47) revealed the enthalpy and entropy barriers $\left(\Delta H^{+}=18.4 \pm 1.7 \mathrm{kcal} \mathrm{mol}^{-1}, \Delta S^{+}=\right.$ $-23.9 \pm 4.9$ e.u.) for the catalytic reaction. The small KIE value, combined with the moderately negative $\Delta S^{+}$value, ${ }^{30}$ effectively rules out the involvement of the cleavage of $\mathrm{H}-\mathrm{H}$ bond in the turnoverdetermining step. To gauge the impact of electron density of the aryl ring on the rate of the hydrogenolysis reaction, we examined the initial rates of a series of para-substituted $(1,2,3,4-$ tetrahydronaphthalen-1-yl)benzene, and created a Hammett plot by plotting $\log \left(k_{\mathrm{X}} / k_{\mathrm{H}}\right)$ against substituent parameters $\sigma_{p}$ (Figure 3B). A negative Hammett parameter $\rho$ of -2.46 was observed, indicative of increased reactivity for electron rich arenes, consistent with the proposed role of the arenes as $\pi$ base in the activation of $\mathrm{H}_{2}$.

To provide further insight into the mechanism, we investigated the hydrogenolysis of 6 with the density functional theory (DFT (M06-2X)) calculations (Figure 3C). ${ }^{31}$ Catalyst $1 \mathrm{a}$ (the $\left[\mathrm{B}\left(\mathrm{C}_{6} \mathrm{~F}_{5}\right)_{4}\right]^{-}$anion was omitted during the calculation, details see supplementary information) first forms a high energy $\mathrm{H}_{2}-$ adduct $1 \mathrm{a}-\mathrm{H}_{2}$ with $\mathrm{H}_{2}$, which in turn reacts with 6 to afford Wheland complex $6-\mathrm{H}^{+}$and neutral borane $1 \mathrm{a}-$ $\mathrm{H}$ via transition state TS1. At TS1, the $\mathrm{H}-\mathrm{H}$ distance is elongated to $1.17 \AA$ with one hydrogen atom $(\mathrm{H} 1)$ interacting with the borenium center $(B-H 1=1.26 \AA)$ and the other hydrogen atom $(\mathrm{H} 2)$ interacting with the ipso-carbon atom of one of the phenyl rings of $\mathbf{6}(\mathrm{C}-\mathrm{H} 2=1.37 \AA)$. A similar transition state was also proposed by Grimme and Stephan for a $\mathrm{B}\left(\mathrm{C}_{6} \mathrm{~F}_{5}\right)_{3}$ mediated hydrogenation of anilines. ${ }^{27}$ The Mulliken charge analysis revealed that the $\mathrm{H} 1$ atom bears a negative charge of -0.16 e and the $\mathrm{H} 2$ atom bears a positive charge of $+0.22 \mathrm{e}$, indicating the heterolytic nature of the $\mathrm{H}-\mathrm{H}$ bond activation. In agreement with experimental observation, the formation of 1-phenylethylium and benzene from the Wheland complex 6$\mathrm{H}^{+}$is the turnover-determining step which needs to overcome an overall free energy barrier of $28.1 \mathrm{kcal}$ $\mathrm{mol}^{-1}$, comparable to the experimental value of $25.5 \pm 2.2 \mathrm{kcal} \mathrm{mol}^{-1}(298 \mathrm{~K})$. The subsequent barrier for the generation of ethylbenzene and catalyst $1 \mathrm{a}$ is very small $\left(6.1 \mathrm{kcal} \mathrm{mol}^{-1}\right)$. The overall reaction is exergonic with $\Delta G=-10.5 \mathrm{kcal} \mathrm{mol}^{-1}$ at $298 \mathrm{~K}$.

Besides small organic molecules, we also examined the possibility of applying this hydrogenolysis system to recycle aromatic chemicals from polystyrene (PS), the most widely used aromatic plastics. ${ }^{32,33}$ Stirring a solution of laboratory-grade polystyrene (PS1, $106 \mathrm{mg} ; M_{\mathrm{W}}=3.10 \times 10^{5} \mathrm{~g} \mathrm{~mol}^{-1}$; polydispersity index $(\mathrm{PDI})=2.01)$ and $51 \mu \mathrm{mol}$ of $1 \mathrm{a}\left(5 \mathrm{~mol} \%\right.$ per styrene unit) in $10 \mathrm{~mL}$ of $o-\mathrm{C}_{6} \mathrm{H}_{4} \mathrm{~F}_{2}$ under 5 bar of $\mathrm{H}_{2}$ at $60^{\circ} \mathrm{C}$ for 16 hours resulted in the formation of $52 \mathrm{mg}$ of benzene ( $49 \mathrm{wt} \%$ ) as determined by GC analysis (Figure 4). This corresponds to $65 \%$ of yield based on the phenyl moieties, comparable to the state-of-art heterogeneous polystyrene hydrogenolysis catalyst $\mathrm{Ru} / \mathrm{Nb}_{2} \mathrm{O}_{5}\left(65 \%\right.$ yield of benzene at $\left.300^{\circ} \mathrm{C}\right) .^{34}$ Significantly, benzene is the only low boiling point $\left(<200^{\circ} \mathrm{C}\right)$ product which can be detected by GC analysis (Figure S52). This unprecedented selectivity is in stark contrast to the complex monoarene products obtained from pyrolysis or hydrocracking of PS. ${ }^{34-36}$ In addition to benzene, long-chain phenylalkanes were obtained as $47 \mathrm{mg}$ of colorless oil (44 wt\%) after the removal of the catalyst by flash column chromatography. Gel permeation chromatography analyses showed that the $M_{W}$ of this oil is 674 
$\mathrm{g} \mathrm{mol}^{-1}$ with a PDI of 1.64 , indicating that the main-chain of PS is also cleaved during the hydrogenolysis process. We tentatively assume that the main-chain $\mathrm{C}-\mathrm{C}$ bonds could be cleaved via $\beta$-scission of the carbenium intermediates, ${ }^{37}$ releasing terminal alkenes which could subsequently be hydrogenated in the presence of $1 \mathbf{a}$ (the proposed reaction pathway see Figure S74). ${ }^{38} \mathrm{The}{ }^{1} \mathrm{H}$ NMR analyses confirmed the absence of olefins in the phenylalkane product, as no signals were observed in the region between 3.5 to $6.5 \mathrm{ppm}$. The integration ratio of the aromatic and aliphatic proton signals is $1: 3.95$, which led to estimation that ca. $81 \%$ of phenyl moieties of polystyrene were replaced with hydrogen atoms (deduction details see supplementary information), correlating relatively well with the yield of benzene determined by $\mathrm{GC}$ analysis. The low percentage of $\mathrm{CH}_{3}$ resonances $(0.8$ to $1.0 \mathrm{ppm})$ among the total integration of the aliphatic protons (ca. $6 \%$ ) indicates that the phenylalkane product is mainly composed of phenylsubstituted linear alkanes, which are valuable precursors for the production of biodegradable surfactants. ${ }^{3,39}$ To the best of our knowledge, no precedented synthesis of linear long chain phenylalkanes from PS has been reported. Taken together, ca. $93 \%$ of the weight of PS was successfully converted to valuable aromatic chemicals. To test if this catalytic system could be utilized to upcycle waste PS, we carried out the hydrogenolysis reaction with post-consumer PS from a single-use plastic cup (PS2, $\left.M_{\mathrm{W}}=1.76 \times 10^{5} \mathrm{~g} \mathrm{~mol}^{-1} ; \mathrm{PDI}=2.12\right)$ and expanded PS foam (PS3, $M_{\mathrm{W}}=2.86 \times 10^{5} \mathrm{~g} \mathrm{~mol}^{-1} ; \mathrm{PDI}$ = 2.21). Comparable yields of benzene ( 49 and $47 \mathrm{wt} \%$ for PS2 and PS3, respectively) and phenylalkanes (42 $\mathrm{wt} \%, M_{\mathrm{W}}=600 \mathrm{~g} \mathrm{~mol}^{-1}, \mathrm{PDI}=1.45$ for PS2; $44 \mathrm{wt} \%, M_{\mathrm{W}}=671 \mathrm{~g} \mathrm{~mol}^{-1}, \mathrm{PDI}=1.54$ for PS3) from these post-consumer PS plastics were obtained, revealing remarkable tolerance of the catalytic system to common processing impurities.

In conclusion, by exploiting the synergistic activation of $\mathrm{H}-\mathrm{H}$ bond with an alkylarene and a boron Lewis acid, we have achieved the hydrogenolysis of the $\mathrm{C}($ aryl $)-\mathrm{C}$ (alkyl) bonds of unactivated alkylarenes without directing groups. The potential of this catalytic system was manifested by its application in conversion of post-consumer polystyrene into valuable benzene and long-chain phenylalkanes under near ambient temperature with unprecedented selectivity. Although the turnover numbers of the catalyst still need improvement, this metal-free approach reported herein enables a top-down strategy for the synthesis of organic molecules from complex precursors that remains a challenge for homogenous transition metal systems.

\section{Declarations}

\section{Acknowledgments}

We thank Gangfeng Tang and Liping Wang for their assistance in GC-MS and NMR experiments. Financial support for this work was provided by the National Natural Science Foundation of China (21871051, 21873019, 22071027), Shanghai Science and Technology Committee (19DZ2270100) and Fudan University.

\section{Author contributions}


H.W. conceived the research and designed the project. Y.X. and Y.L. optimized the reaction conditions. Y.X. studied the substrate scope and carried out experimental mechanism investigation. Y.Y studied the hydrogenolysis of polystyrene. Z.H.L. undertook the DFT calculations. H.W. wrote the manuscript with input from all authors. All authors analyzed the results and commented on the manuscript.

\section{Competing financial interests}

The authors declare no competing financial interests.

\section{References}

1. Hsu, C. S. \& Robinson, P. R. Petroleum Science and Technology (Springer, 2019)

2. Ancheyta, J. \& Speight, J. G. Hydroprocessing of Heavy Oils and Residua (CRC Press, 2007).

3. Olah, G. A. \& Molnár, Á. Hydrocarbon Chemistry (2nd Ed.) (Wiley, 2003)

4. Ellis, L. D., Rorrer, N. A., Sullivan, K. P., Otto, M., McGeehan, J. E., Román-Leshko, Y., Wierckx, N. \& Beckham, G. T. Nat. Cata. 4, 539-556 (2021).

5. Vollmer, I., Jenks, M. J. F., Roelands, M. C. P., White, R. J., Harmelen, T. van, de Wild, P., van der Laan, G. P., Meirer, F., Keurentjes, J. T. F. \& Weckhuysen, B. M. Beyond mechanical recycling: giving new life to plastic waste. Angew. Chem. Int. Ed. 59, 15402-15423 (2020).

6. To, C. T. \& Chan, K. S. Catalytic carbon-carbon sigma-bond hydrogenolysis. Tetrahedron Lett. 57, 4664-4669 (2016).

7. Perthuisot, C. \& Jones, W. D. Catalytic Hydrogenolysis of an aryl-aryl carbon-carbon bond with a rhodium complex. J. Am. Chem. Soc. 116, 3647-3648 (1994).

8. Bart, S. \& Chirik, P. J. Selective, Catalytic carbon-carbon bond activation and functionalization promoted by late transition metal catalysts. J. Am. Chem. Soc. 125, 886-887 (2003).

9. To, C. T.; Choi, K. S. \& Chan, K. S. Catalytic carbon-carbon $\sigma$-bond hydrogenation with water catalyzed by rhodium porphyrins. J. Am. Chem. Soc. 134, 11388-11391 (2012).

10. Liou, S.-Y., van der Boom, M. E. \& Milstein, D. Catalytic selective cleavage of a strong C-C single bond by rhodium in solution. Chem. Commun. 687-688 (1998).

11. Chen, K., Li, H., Lei, Z.-Q., Li, Y., Ye, W.-H., Zhang, L.-S., Sun, J. \& Shi, Z.-J. Angew. Chem. Int. Ed. 51, 9851-9855 (2012).

12. Zhu, J., Wang, J. \& Dong, G. Catalytic activation of unstrained C(aryl)-C(aryl) bonds in 2,2'biphenols. Nat. Chem. 11, 45-51 (2019).

13. Zhu, J., Chen, P.-h., Lu, G., Liu, P. \& Dong, G. Ruthenium-catalyzed reductive cleavage of unstrained aryl-aryl bonds: reaction development and mechanistic study. J. Am. Chem. Soc. 141, 18630-18640 (2019). 
14. Power, P. P. Main-group elements as transition metals. Nature 463, 171-177 (2010).

15. Melen, R. L. Frontiers in molecular p-block chemistry: from structure to reactivity. Science 363, 479484 (2019).

16. Legaré, M.-A., Pranckevicius, C. \& Braunschweig, H. Metallomimetic chemistry of boron. Chem. Rev. $119,8231-8261$ (2019).

17. Franck, H.-G. \& Stadelhofer, J. W. Industrial Aromatic Chemistry (Springer, 1988).

18. Wiesenfeldt, M. P., Nairoukh, Z., Dalton, T. \& Glorius, F. Angew. Chem. Int. Ed. 58, 1046010476 (2019).

19. Gozin, M., Weisman, A., Ben-David, Y. \& Milstein, D. Activation of a carbon-carbon bond in solution by transition-metal insertion. Nature 364, 698-701 (1993).

20. Welch, G. C., San Juan, R., Masuda, J. D. \& Stephan, D. W. Reversible, metalfree hydrogen activation. Science 314, 1124-1126 (2006).

21. Stephan, D. W. \& Erker, G. Frustrated Lewis pair chemistry: development and perspectives. Angew. Chem. Int. Ed. 54, 6400-6441 (2015).

22. Stephan, D. W. The broadening reach of frustrated Lewis pair chemistry. Science $\mathbf{3 5 4}$, aaf7229 (2016).

23. Rokob, T. A., Hamza, A., Stirling, A., Soós, T. \& Pápai, I. Turning frustration into bond activation: a theoretical mechanistic study on heterolytic hydrogen splitting by frustrated Lewis pairs. Angew. Chem. Int. Ed. 47, 2435-2438 (2008).

24. Grimme, S., Kruse, H., Goerigk, L. \& Erker, G. The mechanism of dihydrogen activation by frustrated Lewis pairs revisited. Angew. Chem. Int. Ed. 49, 1402-1405 (2010).

25. Olah, G. A. \& Prakash, G. K. S. (eds), Carbocation Chemistry (Wiley, 2004).

26. MacKnight, E. \& McClelland, R. A. A photochemical retro-Friedel-Crafts alkylation. Rapid rearrangement of cyclohexadienyl cations. Can. J. Chem. 74, 2518-2527 (1996).

27. Mahdi, T., Heiden, Z. M., Grimme, S. \& Stephan, D. W. Metal-free aromatic hydrogenation: aniline to cyclohexyl-amine derivatives. J. Am. Chem. Soc. 134, 4088-4091 (2012).

28. Liu, Y., Dong, W., Li, Z. H. \& Wang, H. Methane activation by a borenium complex. Chem 7, 18431851 (2021).

29. Liu, Y., Su, B., Dong, W., Li, Z. H. \& Wang, H. Structural characterization of a boron(III) $\eta^{2}-\sigma-s i l a n e-$ complex. J. Am. Chem. Soc. 141, 8358-8363 (2019).

30. Houghton, A. Y. \& Autrey, T. Calorimetric study of the activation of hydrogen by tris(pentafluorophenyl)borane and trimesitylphosphine. J. Phys. Chem. A 121, 8785-8790 (2017).

31. Zhao, Y. \& Truhlar, D. G. A new local density functional for main-group thermochemistry, transition metal bonding, thermochemical kinetics, and noncovalent interactions. J. Chem. Phys. 125, 194101 (2006).

32. Maul, J., Frushour, B. G., Kontoff, J. R., Eichenauer, H., Ott, K.-H. \& Shade, C. Polystyrene and Styrene Copolymers in Ullmann's Encyclopedia of Industrial Chemistry (Electronic Release 2012, Wiley). 
33. Maharana. T., Negi, Y. S. \& Mohanty, B. Review Article: Recycling of Polystyrene Polym.-Plastics Tech. \& Eng. 46, 729-736 (2007).

34. Jing, Y., Wang, Y., Furukawa, S., Xia, J., Sun, C., Hülsey, M. J., Wang, H., Guo, Y., Liu, X. \& Yan, N. Towards the circular economy: converting aromatic plastic waste back to arenes over a $\mathrm{Ru} / \mathrm{Nb}_{2} \mathrm{O}_{5}$ catalyst. Angew. Chem. Int. Ed. 60, 5527-5535 (2021).

35. Wang, J., Jiang, J., Sun, Y., Zhong, Z., Wang, X., Xia, H., Liu, G., Pang, S., Wang, K., Li, M., Xu, J., Ruan, R. \& Ragauskas, A. J. Recycling benzene and ethylbenzene from in-situ catalytic fast pyrolysis of plastic wastes. Energ. Convers. Manage. 200, 112088 (2019).

36. González-Marcos, M. P., Fuentes-Ordóñez, E. G., Salbidegoitia, J. A. \& GonzálezVelasco, J. R. Optimization of supports in bifunctional supported Pt catalysts for polystyrene hydrocracking to liquid fuels. Topics Catal. 64, 224-242 (2021).

37. Fuentes-Ordóñez, E. G., Salbidegoitia, J. A., González-Marcos, M. P. \& GonzálezVelasco, J. R. Mechanism and kinetics in catalytic hydrocracking of polystyrene in solution. Polym. Degrad. Stabil. 124, 51-59 (2016).

38. Wang, Y., Chen, W., Lu, Z., Li, Z. H. \& Wang, H. Metal-free $H B\left(\mathrm{C}_{6} \mathrm{~F}_{5}\right)_{2}$-catalyzed hydrogenation of unfunctionalized olefins and mechanism study of borane-mediated $\sigma$-bond metathesis. Angew. Chem. Int. Ed. 52, 7496-7499 (2013)

39. Kocal, J. A., Vora, B. V. \& Imai, T. Production of linear alkylbenzenes. Appl. Cata A. 221, 295-301 (2001).

\section{Figures}



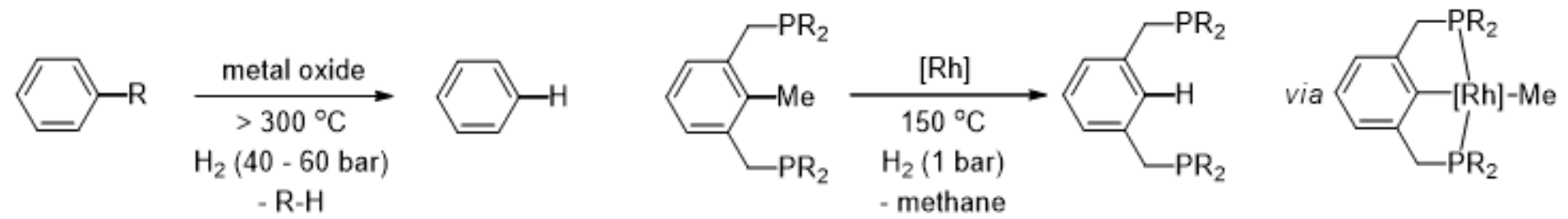

(C) Metal- and directing-group-free hydrodealkylation (this work)

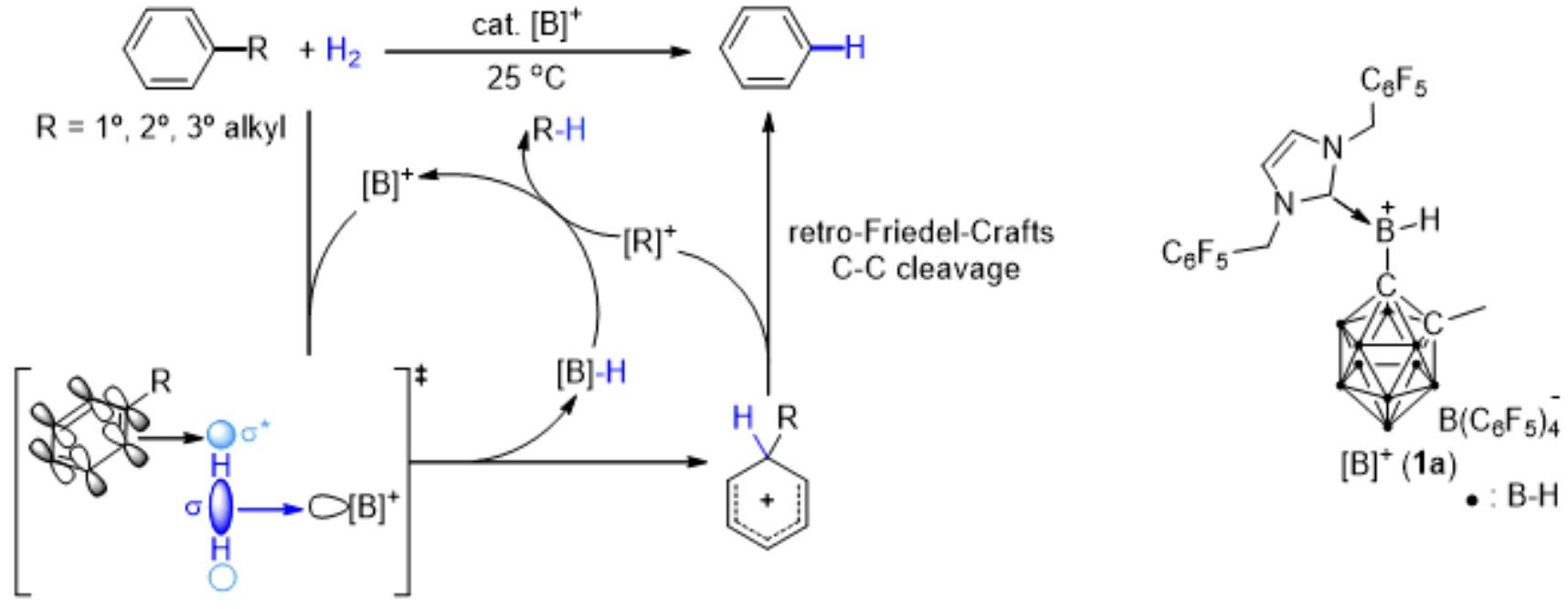

synergistic $\mathrm{H}_{2}$ activation by Lewis-acid / $\pi$-base

\section{Figure 1}

Different approaches of hydrodealkylation. (A) Industrial hydrodealkylation. (B) Directing-group assisted hydrodealkylation. (C) Metal- and directing-group-free hydrodealkylation 

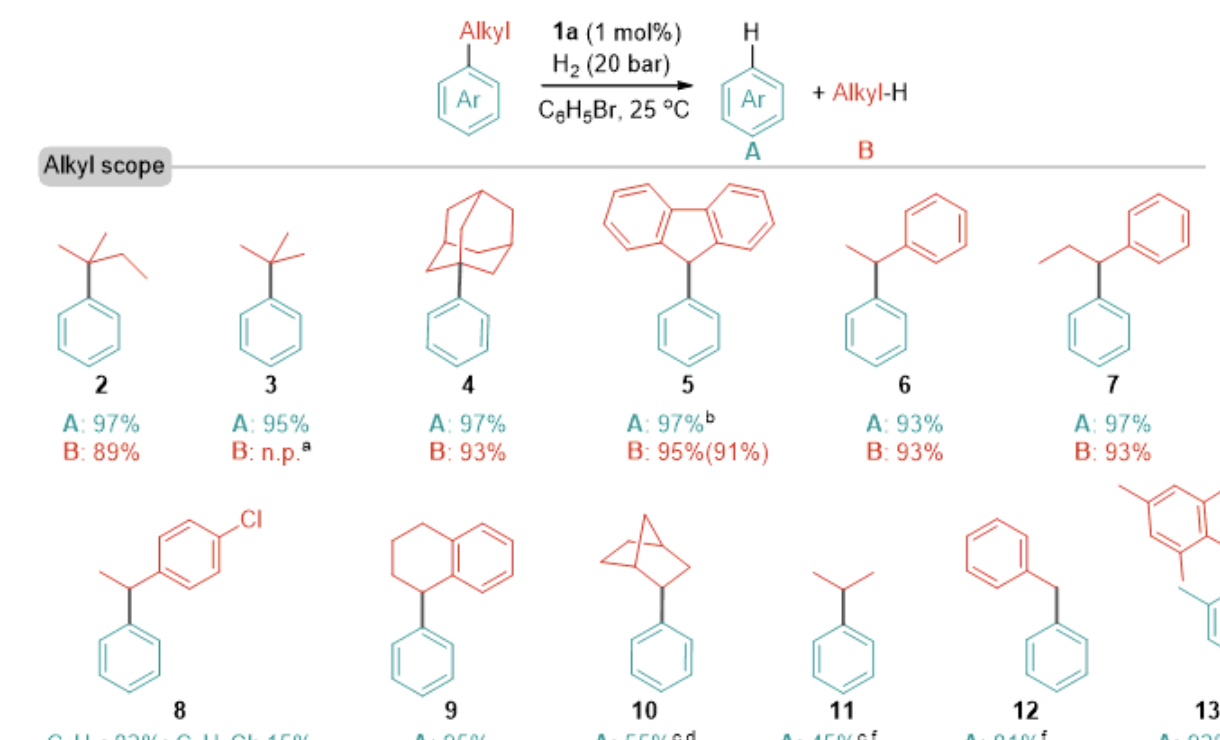

$\mathrm{C}_{8} \mathrm{H}_{8}: 82 \% ; \mathrm{C}_{6} \mathrm{H}_{5} \mathrm{Cl}: 15 \%$ p- $\mathrm{ClC}_{8} \mathrm{H}_{4} \mathrm{Et}: 81 \% ; \mathrm{C}_{6} \mathrm{H}_{5} \mathrm{Et}: 14 \%$
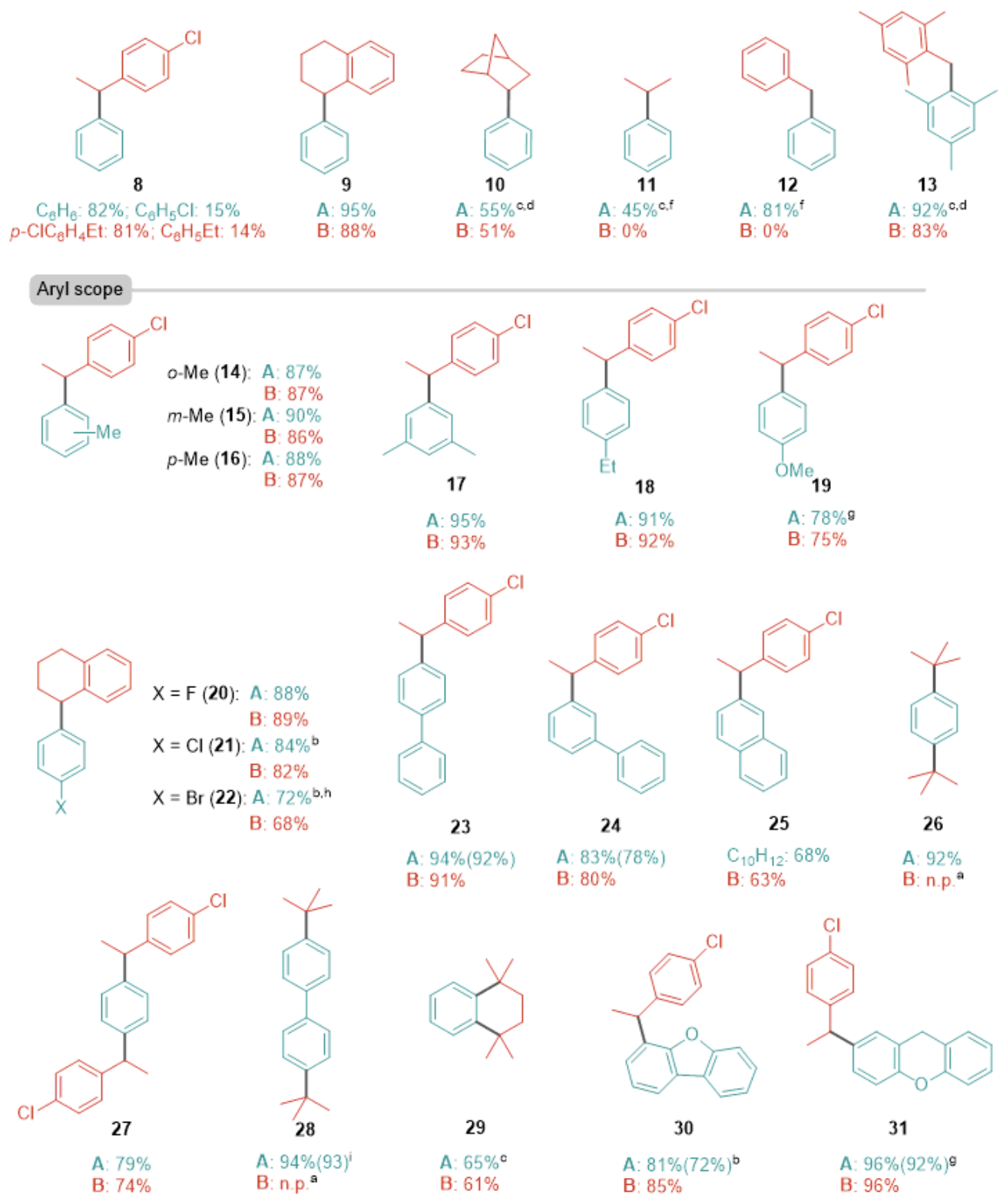

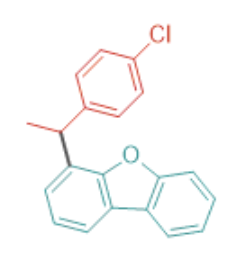

30

A: $81 \%(72 \%)^{b}$ B: $85 \%$

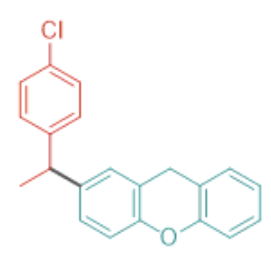

31

A: $96 \%(92 \%)^{9}$ B: $96 \%$

\section{Figure 2}

Substrate scope of of hydrodealkylation. Standard reaction conditions: alkylarenes $(1.0 \mathrm{mmol})$ and $1 \mathrm{a}$ $(0.010 \mathrm{mmol})$ in $\mathrm{C} 6 \mathrm{H} 5 \mathrm{Br}(0.5 \mathrm{~mL})$ under $\mathrm{H} 2(20 \mathrm{bar})$ at room temperature; yields were determined by GC analysis and isolated yields were given in parenthesis. a not pursued; analysis of the overhead gas by GC revealed the presence of isobutane. b 5 mol\% of 1 a was used. c $10 \mathrm{~mol} \%$ of 1 a was used. d o-C6H4F2 was used as solvent. $\mathrm{f}$ transalkylation products between the substrate and solvent were observed. g 20 
mol\% of 1 a was used and the reaction was run at $50^{\circ} \mathrm{C}$. $\mathrm{h} \mathrm{C} 6 \mathrm{H} 5 \mathrm{Cl}$ was used as solvent. i the reaction was carried out in $5 \mathrm{mmol}$ scale.

(A)
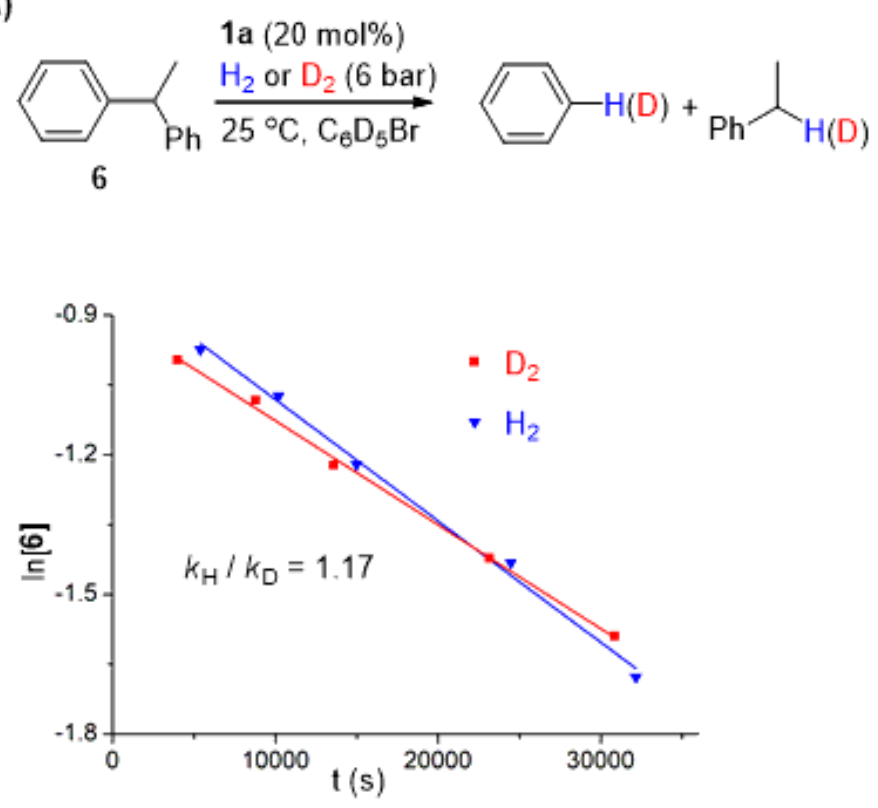

(B)
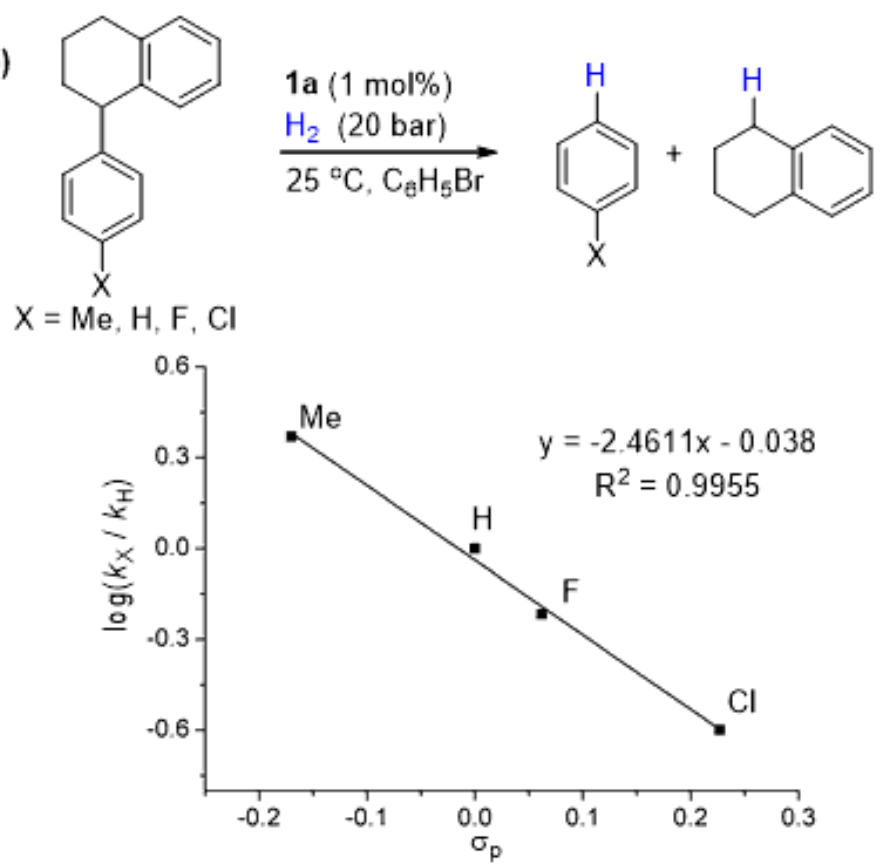

(C)

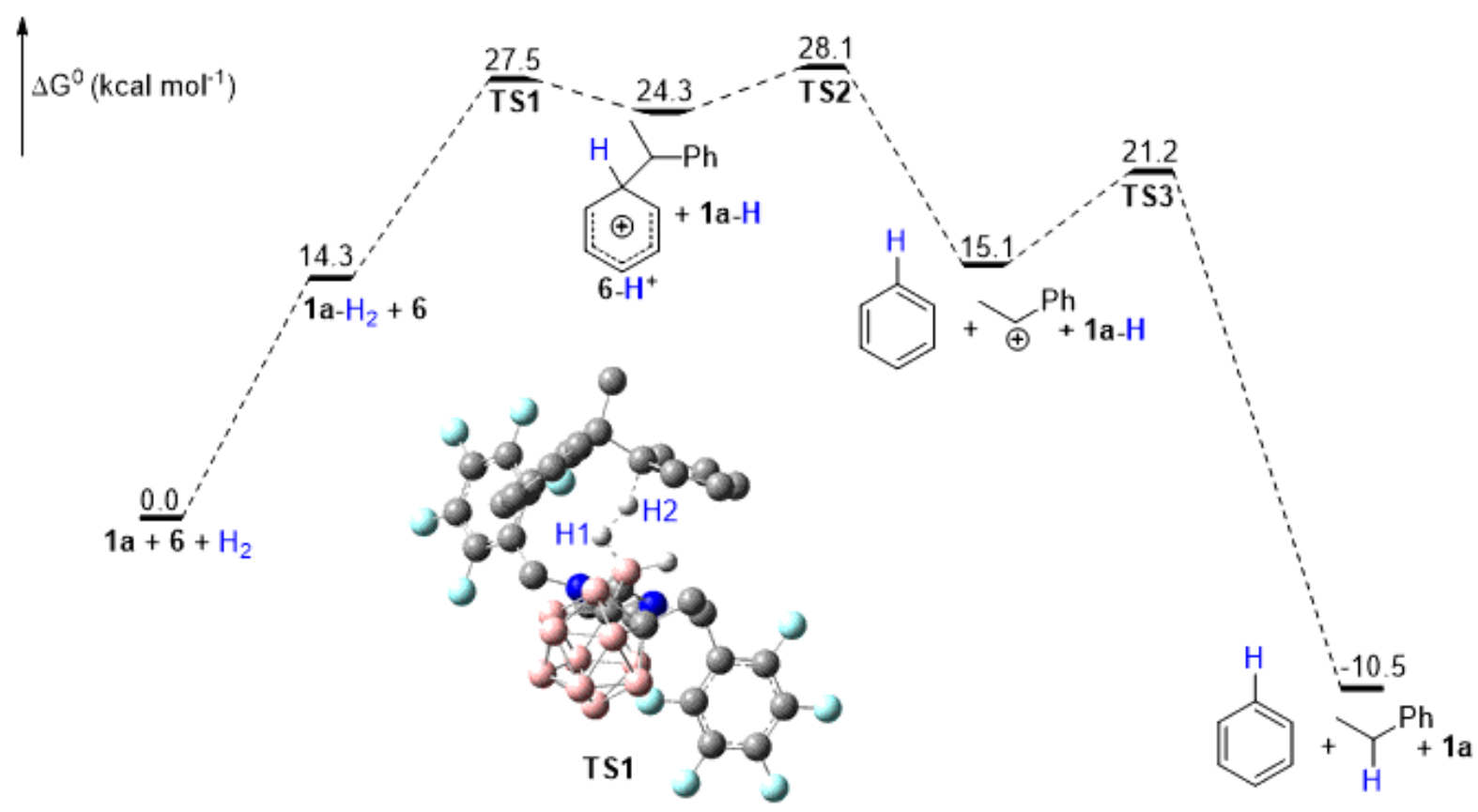

\section{Figure 3}

Mechanism investigation of the hydrogenolysis of 6. (A) KIE study. (B) Hammett plot of In(kX/kH) vs. op for the hydrogenolysis reaction. (C) Gibbs free energy profile at $298 \mathrm{~K}$ for the hydrogenolysis of 6 catalyzed by $1 \mathrm{a}$ and the geometry of TS1 (hydrogen atoms except H1, H2 and the one connected to the borenium center are omitted for clarity) 


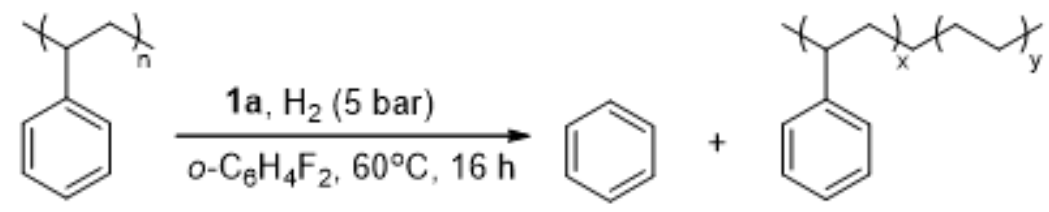

$M_{\mathrm{w}}=1.76 \sim 3.10 \times 10^{5} \mathrm{~g} \mathrm{~mol}^{-1}$

$M_{\mathrm{w}}=600 \sim 674 \mathrm{~g} \mathrm{~mol}^{-1}$

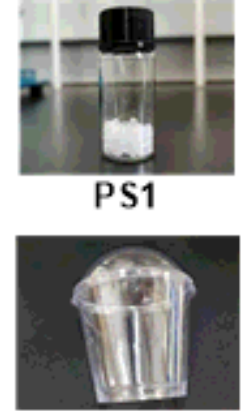

PS2

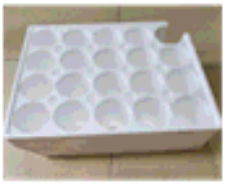

PS3

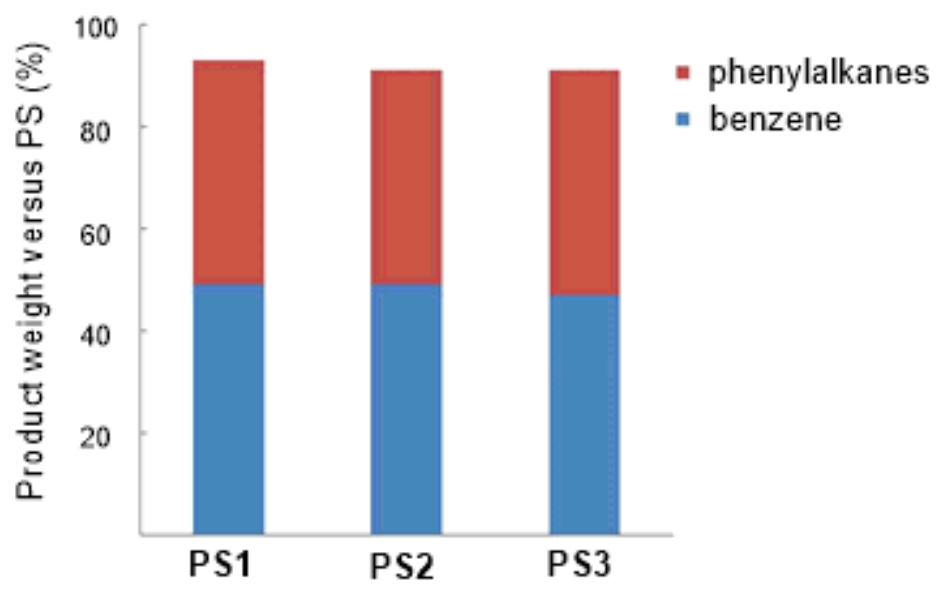

Figure 4

Hydrogenolysis of polystyrene with 1a as catalyst. PS1: laboratory-grade polystyrene; PS2: polystyrene single-use cup; PS3: expanded polystyrene foam. Reactions were run with $0.1 \mathrm{~g}$ of polystyrene and 0.05 mmol of $1 \mathrm{a}$ in o-C6H4F2 $(10 \mathrm{~mL})$ under 5 bar of $\mathrm{H} 2$ at $60^{\circ} \mathrm{C}$.

\section{Supplementary Files}

This is a list of supplementary files associated with this preprint. Click to download.

- supplementaryinformation.pdf 